Teaching the unlearnable: A training study of complex yes/no questions

\begin{tabular}{|r|l|}
\hline Journal: & Journal of Child Language \\
\hline Manuscript ID & Draft \\
\hline Manuscript Type: & Article \\
\hline Keywords: & $\begin{array}{l}\text { Structure dependence, subject-auxiliary inversion, poverty of the } \\
\text { stimulus }\end{array}$ \\
\hline
\end{tabular}

SCHOLARONE $^{m}$
Manuscripts 
Teaching the unlearnable:

A training study of complex yes/no questions 


\section{Teaching the unlearnable: A training study of complex yes/no questions}

A central question in language acquisition is how children master sentence types that they have seldom, if ever, heard. Here we report the findings of a preregistered, randomized, single-blind intervention study designed to test the prediction that, for one such sentence type, complex questions (e.g., Is the crocodile who's hot eating?), children could combine schemas learned, on the basis of the input, for complex noun phrases (the [THING] who's [PROPERTY]) and simple questions (Is [THING] [ACTION]ing?) to yield a complexquestion schema (Is [the [THING] who's [PROPERTY]] ACTIONing?). To investigate this possibility, 122 children aged $4 ; 2$ to $6 ; 8$ years $(M=5 ; 6, S D=7.7$ months) were trained on simple questions (e.g., Is the bird cleaning?) and either (Experimental group, $N=61$ ) complex noun phrases (e.g., the bird who's sad) or (Control group, $N=61$ ) matched simple noun phrases (e.g., the sad bird). On most measures, the two groups did not differ on their ability to produce novel complex questions at test. However, the Experimental group did show some evidence of generalizing a particular complex NP schema (the [THING] who's [PROPERTY] as opposed to the [THING] that's [PROPERTY]) from training to test; a finding that is potentially compatible with constructivist, generativist and task-based explanations. 


\section{Teaching the unlearnable: A training study of complex yes/no questions}

Few questions are more central to our understanding of cognitive development than that of how children learn to produce sentences in their native language. For sentences that children have frequently heard in exactly that form (e.g., the question What's that?; typically one of the first produced by learners of English; e.g., Ambridge, Rowland, Theakston \& Lieven, 2006) the answer is potentially straightforward: Children repeatedly hear the form paired with a particular inferred meaning (in this case, something like "I request that you produce the conventional label for this object"), and so produce this form when they want to convey this meaning themselves. For sentences that children have not heard (e.g., The hungry mouse chased the shy panda) the problem is considerably more difficult, but it is still tractable. Children hear very many sentences of the same type (e.g., The old man bought a new book; The little girl ate a delicious cake), and generalise based on the shared properties of basic two-participant sentences (e.g. shared sentence structure, meaning, syntactic or semantic roles) ; though the precise nature of this generalization varies considerably from theory to theory (e.g., Pinker, 1984; Wexler, 1998; Tomasello, 2003; Sakas \& Fodor, 2012).

But for a third type of sentence, the problem appears completely intractable. Consider, for example, the sentence Is the crocodile who's hot eating? (an example from the present study). Not only have children never heard this PARTICULAR sentence (a Google search yields no results), they will have rarely, if ever, heard ANY sentence of this form (i.e., a yes/no question that contains a relative clause [e.g., who's hot]). In a search of approximately 3 million child-directed utterances in the CHILDES database, MacWhinney (2004) found only a single example (c.f., Cowie, 1998; Pullum \& Scholz, 2002). Yet, although children struggle with these complex-questions (showing around only 65\% accuracy at age 6-7; Ambridge, Pine \& Rowland, 2008), at some point in the transition to adulthood, they master them.

How, then, do children "learn the unlearnable" (Regier \& Gahl, 2003: 147)?

Historically (e.g., Chomsky, 1980; Crain \& Nakayama, 1987) a popular answer has been that that they cannot. Children cannot learn this rule from the input, and master it only with two pieces of innate knowledge (i.e., knowledge with which learners are born). The first is knowledge that some languages use a movement rule to transform statements into questions by moving the auxiliary (here, is) [1]:

\section{[1] the crocodile is eating $\rightarrow$ is the crocodile eating?}

The second is knowledge that this rule is structure dependent (i.e., is formulated in terms of the structural constituents of the sentence as opposed to, say, the linear ordering of the words). For complex questions in English, the correct structure-dependent rule is 'move the auxiliary in the main clause' [2]:

\section{[2] the crocodile who's hot is eating $\rightarrow$ is the crocodile who's hot eating?}

and not (for example) 'move the second auxiliary' [3]:

\section{[3] the crocodile who's hot is eating $\rightarrow$ *is the crocodile who $=$ hot is eating?}

Indeed, the ability of children to produce complex questions without ever hearing them is often taken as the "parade case" (Crain, 1991: 602) for innate knowledge of language (see also Crain \& Pietroski, 2001; Laurence \& Margolis, 2001; Fodor \& Crowther, 2002; Legate \& Yang, 2002; Kam, Stoyneshka, Tornyova, Fodor \& Sakas, 2008; Berwick, Pietroski, Yankama \& Chomsky, 2011). 
Our goal in the present paper is to investigate a different possibility: that, although children never hear complex questions, they learn to produce them by combining constructions that they have learned from the input (Stemmer, 1981; Sampson, 1989; Ambridge et al, 2008; Ambridge \& Rowland, 2009; Clark \& Lappin, 2011; Fitz \& Chang, 2017; see also Lewis \& Elman, 2001; Reali \& Christiansen, 2005; Perfors, Tenenbaum \& Regier, 2011, for alternative learning approaches). Intuitively, the idea is a very simple one. Children hear thousands of simple yes/no questions, and schematize across them (Tomasello, 2003) to form a slot-and-frame pattern, which allows them to produce new questions by inserting new items into the slots (e.g., Dąbrowska, 2000; Dąbrowska \& Lieven, 2005; Rowland, 2007):

Is the bird cleaning?

Is the fish swimming?

Is the whale falling?

Is the frog clapping?

\section{Is [THING] [ACTION]ing?}

Similarly, children hear thousands of complex noun phrases, and schematize across them to produce a slot-and-frame pattern which allows for the production of new exemplars:

the cow who's small

the bird who's big

the dog who's white

the mouse who's black

the [THING] who's [PROPERTY]

The final, crucial, step is schema-combination: The complex-noun-phrase schema the [THING] who's [PROPERTY] itself denotes a THING, and so can be inserted into the [THING] slot of the yes/no question schema:

\section{Is [the [THING] who's [PROPERTY]] ACTIONing?}

Surprisingly, given its centrality to the issue of language learnability, the question of whether children can learn to produce complex questions by schema combination has never been tested. In the present article, we report a pre-registered, randomized, single-blind intervention study designed to answer the question. An experimental group were given training on simple yes/no questions and complex noun phrases, as in the examples above. A control group (matched for language ability) were given training on simple yes/no questions and - instead of complex noun-phrases - semantically-matched simple adjectival noun phrases (e.g., the small cow and the big bird rather than the cow who's small and the bird who's big). Our preregistered hypothesis was that the experimental group would outperform the control group on both (a) the number of correct complex questions produced and (b) the number of children able to produce at least one correct complex question.

\section{Ethics and preregistration}

\section{Method}

This study was approved by the University of Liverpool Ethics Committee. The methods, hypotheses, sampling and analysis plan were registered at https://osf.io/wcp6t/register/565fb3678c5e4a66b5582f67 prior to the collection of any data. All training and test materials, and anonymized raw data, can be found at https://osf.io/wcp6t/ 


\section{Participants}

A preregistered sample size of 122 children (61 per group, randomly allocated) was determined on the basis of a power calculation with $d=0.3$, power $=0.5$, on the basis of a between-subjects $t$-test (using GPower 3.0). Although our analysis plan actually specified the use of mixed-effects models, it is not possible to run a power analysis for such models without simulated data, and we were not aware of any findings from studies with sufficiently similar methods to form the basis for such a simulation. Although a power greater than 0.5 would have been desirable, a total sample size of 122 was our maximum in terms of time, funding and personnel. We go some way towards mitigating this problem by also including a supplementary, exploratory Bayesian analysis (the decision to add this analysis was taken after the main results were known). A total of 143 children completed the experiment, but 21 were excluded ( 9 from the Experimental group and 12 from the Control group) for failing to meet the preregistered training criteria set out below. Children were recruited from UK Reception (aged 4-5 years) and Year 1 (5-6 years) classes. The final sample ranged from 4;2 to $6 ; 8, M=5 ; 6, S D=7.7$ months, Experimental group $=\mathrm{M}=64.85$ months, $\mathrm{SD}=7.93$; Control group $=\mathrm{M}=66.54$ months, $\mathrm{SD}=7.44$ )

\section{Standardized test}

Before training, all participants completed the Word Structure test from the fifth edition of the CELF-Preschool 2 UK (Wiig, Secord \& Semel, 2004). This is a production test of morphosyntax, in which children are asked to complete sentences to describe pictures (e.g., Experimenter: This girl is climbing. This girl is ... Child: Sleeping). The purpose of this test was to allow us to verify that the Experimental and Control groups were matched for general ability with morphosyntax. This was found to be the case (Experimental: $M=19.42, S D=3.05$; Control: $M=19.95, S D=2.79)$. We did not include a baseline measure of complex-question production because we did not want to give children practice in producing these questions, since our goal was to investigate the impact of relevant training on children who had previously heard no - or extremely few - complex questions.

\section{Training}

All participants completed five training sessions on different days. As far as possible, children were tested on five consecutive days, but sometimes this was not possible due to absence. The total span of training (in days) for each child was included as a covariate in the statistical analysis. Each daily training session comprised two sub-sessions: Noun-Phrases and simple yes/no questions, always in that order. The CELF was presented immediately before the first training session on Day 1; The complex-question test session immediately after the final training session on Day 5.

Noun-phrase (NP) training. The aim of this part of the session was to train children in the Experimental group on complex noun phrases (e.g., the bird who's happy), resulting in the formation of a complex-noun-phrase schema (the [THING] who's [PROPERTY]) that could be combined with a simple question schema (Is [THING] [ACTION]ing?) to yield a complex-question schema (Is [the [THING] who's [PROPERTY]] ACTIONing?). On each day, children in the Experimental group heard the experimenter produce 12 such complex noun phrases (see Table 1, first column), and heard and repeated a further 12 such phrases (see Table 1, second column).

NP training took the form of a bingo game, in which the experimenter and child took turns request cards from a talking dog toy, in order to complete their bingo grid, with the experimenter helping the child by telling her what to say. The dog's responses were structured such that the child always won the bingo game on Days 1, 3 and 5, and the 
experimenter on Days 2 and 4, resulting in an overall win for the child. In order to provide pragmatic motivation for the use of complex noun phrases (e.g., the bird who's sad, as opposed to simply the bird), the bingo grid contained two of each animal, with opposite properties (e.g., the bird who's happy vs the bird who's sad; the chicken who's big vs the chicken who's small), requested on subsequent turns by the child and the experimenter (as shown in Table 1). Two different versions of the game were created, with different pairings of animals and adjectives, the first used on Days 1, 3 and 5, the second on Days 2 and 4. The allocation of NPs to the experimenter versus the child, and the order of the trials was varied within each version, but was not subject to any between-subjects variation: Within a particular group (Experimental/Control) all children had identical training.

Children in the control group received similar training to the Experimental group, except that instead of complex NPs (e.g., the bird who's happy), they heard and repeated semantically-matched simple adjectival NPs (e.g., the happy bird), as shown in the two rightmost columns of Table 1 .

\section{Table 1. Day 1 Noun-phrase training for children in the Experimental and Control Groups. Children heard each NP in the "Experimenter" column, and heard and repeated each NP in the "Child" column.}

\section{Experimental Group}

Experimenter

the bird who's happy the fish who's happy the whale who's sad the frog who's sad the chicken who's big the cow who's big the bear who's small the horse who's small the dog who's black the cat who's black the mouse who's white the rabbit who's white

Child
the bird who's sad
the fish who's sad
the whale who's happy
the frog who's happy
the chicken who's small
the cow who's small
the bear who's big
the horse who's big
the dog who's white
the cat who's white
the mouse who's black
the rabbit who's black

Experimenter the happy bird the happy fish the sad whale the sad frog the big chicken the big cow the small bear the small horse the black dog the black cat the white mouse the white rabbit

\section{Control Group}

Child
the sad bird
the sad fish
the happy whale
the happy frog
the small chicken
the small cow
the big bear
the big horse
the white dog
the white cat
the black mouse
the black rabbit

Simple-question training. The aim of this part of the session was to train children on simple questions (e.g., Is the bird cleaning?), resulting in the formation of a simple question schema (Is [THING] [ACTION]ing?) that children in the Experimental group - but crucially not the Control group - could combine with the trained complex-noun-phrase schema (the [THING] who's [PROPERTY]) to yield a complex-question schema (Is [the [THING] who's [PROPERTY]] ACTIONing?). Simple question training was identical for the Experimental and Control groups, and took the form of a game in which the child repeated questions spoken by the experimenter (see Table 2), subsequently answered by the same talking dog toy from the NP training part of the session.

The experimenter first explained that "We are going to ask the dog some questions. We'll see an animal on the card and try to guess what the animal is doing on the other side of the card". On each trial, the experimenter first showed the face of the card depicting the animal doing nothing in particular and said, for example, "On this one, here's a bird. I wonder if the bird is cleaning. Let's ask the dog. Copy me. Is the bird cleaning”. After the child had attempted to repeat the question, the dog responded (e.g., "No, he's having his 
dinner"), and the experimenter turned the card to show an illustration depicting the answer. As for the NP training, two different versions of the game were created, with different pairings of animals and actions, the first used on Days 1, 3 and 5, the second on Days 2 and 4 , with the order of presentation varied within each version. All children, regardless of group, had identical simple-question training. Note that, in order to encourage schema combination, an identical set of animals featured in the NP (e.g, the bird who's sad) and complex-question training (e.g., is the bird cleaning?).

\section{Table 2. Day 1 simple-question training for all children.}

\section{Experimenter says, child repeats...}

Is the bird cleaning?

Is the fish swimming?

Is the whale falling?

Is the frog clapping?

Is the chicken crying?

Is the cow drinking?

Is the bear drawing?

Is the horse painting?

Is the dog walking?

Is the cat jumping?

Is the mouse laughing?

Is the rabbit hopping?

\section{Talking dog toy answers}

No, he's having his dinner

Yes, he's swimming in the pond

No, he's OK!

No, he's croaking

Yes, he's a bit sad today

Yes, he's drinking some water

No, he's having his breakfast

No, he's going for a run

No, he's fetching his ball

Yes, he's jumping up and down

Yes, he heard a funny joke

Yes, and he's having lots of fun

Test phase: complex questions. The aim of the test phase was to investigate children's ability to produce complex questions (e.g., Is the crocodile who's hot eating?) by combining trained complex-NP and simple-question schemas ((Is [the [THING] who's [PROPERTY] ACTIONing?). Because we were interested in training an abstract schema, rather than particular lexical strings, the target complex questions for the test phase used only animals, verbs and adjectives that were not featured during training (see Table 3).

The game was very similar to that used in the simple-question training, except that children were told "This time you are not going to copy me. I will tell you what to ask, and you can ask the dog". For each trial, the experimenter held up the relevant card and said (for example). "Two crocodiles: hot and cold [points to each crocodile; one wearing swimwear on a beach; the other wearing winter clothing in snow]. I wonder if the crocodile who's hot is eating. Ask the dog if the crocodile who's hot is eating". Note that this prompt (equivalent to that used in Ambridge et al, 2008) precludes the possibility of the child producing a wellformed question simply by repeating part of the experimenter's utterance. As before, the dog then answered (e.g., "Yes, he's having his breakfast"), and the experimenter turned the card to show the relevant animation. Each child completed 12 test trials in random order.

\section{Table 3. Complex-question test session (Day 5) for all children.}

\begin{tabular}{|l|l|}
\hline Child's target complex question & Talking dog toy answers \\
\hline Is the crocodile who's hot eating? & Yes, he's having his breakfast \\
\hline Is the penguin who's cold dancing? & No, he's skating \\
\hline
\end{tabular}




\begin{tabular}{|l|l|}
\hline Is the elephant who's thin hiding? & Yes, he doesn't want anyone to find him \\
\hline Is the giraffe who's fat driving? & Yes, he's driving in his car \\
\hline Is the goat who's tall singing? & No, he's not very good at singing \\
\hline Is the hedgehog who's short playing? & No, he's having his dinner \\
\hline Is the lion who's clean running? & Yes, he's really fast \\
\hline Is the monkey who's dirty climbing? & Yes, he's going really high up in the tree \\
\hline Is the panda who's heavy cooking? & Yes, he's making his tea \\
\hline Is the tiger who's light sitting? & No, he's going for a walk \\
\hline Is the zebra who's fast waving? & No, he's trying to catch a fly \\
\hline Is the duck who's slow flying? & No, he's saying "quack quack" \\
\hline
\end{tabular}

\section{Exclusion criteria}

In order to ensure that both the Experimental and Control groups were made up of children who had successfully completed the training, we followed our preregistered exclusion criteria, which specified that "any child who does not correctly repeat at least half of the noun phrases and at least half of the questions on all five days will be excluded... All children who complete the training and test to criterion (outlined above) will be included, and any who do not will be replaced". On this criterion, we excluded 21 children.

\section{Coding}

All participants produced scorable responses for all trials, with no missing data (i.e., all responses were clearly some attempt at the target question). Presumably this was due to our extensive training and strict exclusion criteria which ensured that children were competent and confident in putting questions to the talking dog in response to prompts from the experimenter. Responses were coded according to the scheme shown in Table 4, which also shows the number of responses in each category, for each group. As detailed below, these counts reflect the use of a lenient version of the coding scheme which allows (i.e., ignores) production of that in place of who.

\begin{tabular}{|c|c|c|c|c|}
\hline Classification & Description & Example & $N \operatorname{Exp}$ & $N \mathrm{Ctrl}$ \\
\hline Correct & $\begin{array}{l}\text { Exact production of } \\
\text { the target question } \\
\text { or } \\
\text { with production of } \\
\text { that in place of who }\end{array}$ & $\begin{array}{l}\text { Is the crocodile who's hot } \\
\text { eating? } \\
\text { Is the crocodile that's hot } \\
\text { eating? }\end{array}$ & 308 & 209 \\
\hline Repetition & $\begin{array}{l}\text { Any utterance } \\
\text { starting "I wonder" }\end{array}$ & $\begin{array}{l}\text { I wonder if the crocodile } \\
\text { who/that's hot is eating? }\end{array}$ & 2 & 11 \\
\hline Aux-doubling & $\begin{array}{l}\text { Otherwise well- } \\
\text { formed question with } \\
\text { "doubled" auxiliary }\end{array}$ & $\begin{array}{l}\text { Is the crocodile who/that's } \\
\text { hot is eating? }\end{array}$ & 101 & 209 \\
\hline Resumptive & $\begin{array}{l}\text { As Aux-doubling but } \\
\text { with resumptive } \\
\text { pronoun }\end{array}$ & $\begin{array}{l}\text { Is the crocodile who/that's } \\
\text { hot, is she/he/it eating? }\end{array}$ & 18 & 15 \\
\hline Statement & $\begin{array}{l}\text { Complex utterance } \\
\text { but phrased as a } \\
\text { statement/intonation } \\
\text { question rather than a }\end{array}$ & $\begin{array}{l}\text { The crocodile who/that's } \\
\text { hot is eating? }\end{array}$ & 69 & 21 \\
\hline
\end{tabular}


In order to check reliability, all responses were independently coded by two coders: the first and final author. At the first pass, the coders showed 100\% agreement with regard to the classification of responses as correct (1) or erroneous (0), with the only disagreements relating to the classification of error types (84 cases for an overall agreement rate of $94.3 \%$ ). All of these discrepancies related to ambiguities in the coding scheme and, following discussion, were eliminated for $100 \%$ agreement.

\section{Predictions}

Our two pre-registered predictions were as follows:

1. The experimental group will produce significantly more correctly-formed complex questions (out of a maximum of 12) than the control group (as determined by maximal mixed effects models; e.g., Barr et al, 2013).

2. Significantly more children in the experimental than control group will produce at least one correctly formed question (as determined by chi-square test).

The reason for including this second prediction, despite the fact that, as a categorical statistic, the chi-square test has much lower power, was that it taps more directly into the question of whether our training regime is sufficient to "create" the ability to produce a complex yes/no question, as opposed to simply boosting this ability.

\section{Analyses}

The data were analysed according to our preregistered analysis plan. To compare the number of correct questions produced by each group, we ran a linear mixed effects regression model in R (R Core Team, 2017) with random intercepts for participant and item, using the lme4 package (Bates, Maechler, Bolker \& Walker, 2015). No random slopes were included because, as per the analysis plan, we simplified the model using the procedure outlined by Barr et al (2013), in order to enable convergence. With one exception, we were able to include all the fixed effects specified in the analysis plan: Group (Experimental vs Control; coded as 1 vs 0), Age in months, Score on the standardized grammar test (CELF Word Structure), Days taken to complete the five training blocks, and Number of noun phrases correctly repeated during training. However, in order to enable the model to converge, it was necessary to remove the nonsignificant predictor that explained the least variance: Number of simple questions correctly repeated during training. P values were obtained using the modelcomparison (likelihood ratio test) procedure. To compare the number of participants in the 
experimental and control groups producing at least one correct complex question, we ran a $2 \times 2$ chi square analysis: Group (Experimental/Control) $\mathrm{x}$ children producing/not producing at least one correctly-formed complex question

\section{Results}

Table 4 shows the outcome of the linear mixed effects regression analysis. As predicted, the Experimental group significantly outperformed the control group on the proportion of correct questions produced ( $M=0.42, S D=0.49$ vs $M=0.29, S D=0.45$, Chi-square $=6.18, p=0.013$ ). However, this finding is contingent upon a very strict interpretation of the "Correct" question criterion, which requires children to produce exactly the target question, with no substitutions (e.g., Is the crocodile who's hot eating?). If this criterion is relaxed to allow substitution of complementizer that for who (e.g., Is the crocodile that's hot eating?; 99 instances across the two groups), no significant difference between the Experimental and Control groups is seen $(M=0.44, S D=0.50$ vs $M=0.40, S D=0.49$, Chi-square $=1.86, p=0.17$, n.s $)$; see Table 5 .

Unfortunately, we failed to anticipate the possibility of that-for-who substitutions in our preregistration, and so did not specify in advance whether or not we would score such utterances as correct.

Table 4. Model and model comparisons using strict coding scheme

\begin{tabular}{|c|c|c|c|c|c|c|c|c|}
\hline \multirow[b]{2}{*}{ Fixed Effect } & \multicolumn{4}{|c|}{ Model } & \multicolumn{4}{|c|}{ Model Comparisons } \\
\hline & Estimate & SE & $\mathrm{z}$ value & $\mathbf{p}(\mathbf{z})$ & AIC & ChiSq & p (ChiSq) & \\
\hline (Intercept) & -13.80 & 3.98 & -3.47 & 0.001 & 1184.80 & (Full model) & & \\
\hline Group $=\operatorname{Exp}($ vs Control $)$ & 1.52 & 0.61 & 2.50 & 0.013 & 1189.00 & 6.18 & 0.013 & $*$ \\
\hline Age (Months) & 0.07 & 0.04 & 1.55 & 0.120 & 1185.20 & 2.41 & 0.120 & \\
\hline Test Period (Days) & -0.17 & 0.20 & -0.83 & 0.407 & 1183.50 & 0.69 & 0.405 & \\
\hline Word Structure CELF & 0.44 & 0.12 & 3.53 & 4.E-04 & 1195.90 & 13.08 & 3.E-04 & $* * *$ \\
\hline TrainingNPs Repeated & -0.17 & 0.21 & -0.83 & 0.407 & 1183.50 & 0.68 & 0.408 & \\
\hline
\end{tabular}

Table 5. Model and model comparisons using lenient coding scheme

Model

\begin{tabular}{lrrrr}
\multicolumn{1}{c}{ Fixed Effect } & Estimate & SE & z value & p (z) \\
\hline (Intercept) & -16.24 & 3.67 & -4.43 & 1. E-05 \\
Group = Exp (vs Control) & 0.74 & 0.55 & 1.37 & 0.172 \\
Age (Months) & 0.10 & 0.04 & 2.37 & 0.018 \\
Test Period (Days) & -0.01 & 0.18 & -0.08 & 0.940 \\
Word Structure CELF & 0.50 & 0.11 & 4.44 & $9 . \mathrm{E}-06$ \\
TrainingNPs Repeated & -0.27 & 0.20 & -1.35 & 0.176
\end{tabular}

Model Comparisons

\begin{tabular}{lrrrr}
\multicolumn{1}{l}{ AIC } & ChiSq & p (ChiSq) & \\
\cline { 1 - 2 } 1228.60 & & & & \\
1228.50 & 1.86 & 0.173 & \\
1232.20 & 5.62 & 0.018 & $*$ \\
1226.60 & 0.01 & 0.940 & \\
1247.50 & 20.85 & $5 . \mathrm{E}-06$ & $* * *$ \\
1228.50 & 1.87 & 0.172 &
\end{tabular}

Table 6. Bayesian model using lenient coding scheme

\begin{tabular}{|c|c|c|c|c|c|c|c|}
\hline Fixed Effect & Estimate & SE & $\begin{array}{l}95 \text { CI } \\
\text { Lower }\end{array}$ & $\begin{array}{l}95 \text { CI } \\
\text { Upper }\end{array}$ & $\begin{array}{c}\text { Eff } \\
\text { Samples }\end{array}$ & Rhat & $\mathrm{p}(\mathrm{MCMC})$ \\
\hline
\end{tabular}




$\begin{array}{rrr}-14.46 & 4.93 & -24.19 \\ 0.71 & 0.58 & -0.44 \\ 0.10 & 0.04 & 0.01 \\ -0.03 & 0.21 & -0.42 \\ 0.53 & 0.13 & 0.28 \\ -0.27 & 0.21 & -0.67 \\ -0.49 & 0.58 & -1.66\end{array}$

$\begin{array}{rrr}-4.78 & 2026.00 & 1.00 \\ 1.83 & 1147.00 & 1.00 \\ 0.19 & 966.00 & 1.01 \\ 0.38 & 1055.00 & 1.00 \\ 0.80 & 1073.00 & 1.00 \\ 0.15 & 1151.00 & 1.00 \\ 0.61 & 6112.00 & 1.00\end{array}$

Because null results are difficult to interpret, particularly for studies with relatively low power, we additionally ran a Bayesian mixed-effects model with a wide prior for all predictor variables $(M=0, S D=2)$, using brms (Bürkner, 2017). This model was run only for data coded using the lenient coding scheme. Because Bayesian models are more robust to convergence failure, we were able to build a maximally conservative model with by-item random slopes for group, age, score on the CELF Word Structure test, days taken to complete the training and the number of (a) simple questions and (b) noun phrases correctly repeated during training. This model is shown in Table 6. Although the credible interval for the effect of group (Experimental vs Control) includes zero $(M=0.71[-0.44,1.83])$, we do not see a distribution that would constitute positive evidence for the ABSENCE of this effect; i.e., a narrow credible interval centred around zero. Indeed, the $p M C M C$ value of 0.105 indicates a $90 \%$ probability of an effect of group greater than zero. Thus, we cannot rule out the possibility that a between-groups difference may have been observed on this measure, had we been able to achieve greater power through the use of a larger sample.

However, given that the aim of the study was to train a complex question structure, potentially more informative (if less sensitive) is the chi-square analysis of children who produced/failed to produce at least one complex question. This analysis found no difference between groups using either the strict coding criteria (Experimental Group: 40/61 vs Control Group 35/61; Chi-square $=0.55, p=0.46$, n.s.) or the lenient criteria (Experimental Group: 41/61 vs Control Group 42/61; Chi-square $=0, p=1$, n.s.). The fact that, even with no training (i.e., in the Control Group), around two-thirds of children were able to produce at least one correctly-formed question suggests one possible reason for our failure to observe an effect of our experimental manipulation on the lenient criteria: The training was superfluous because most children of this age and from this population already have the ability to form complex questions, a least with that, if not with who.

\section{Discussion}

A central question in language acquisition is how children master sentence types that they have seldom, if ever, heard. The aim of the present study was to test the prediction that, for one such sentence type, complex questions (e.g., Is the crocodile who's hot eating?), children could combine schemas learned, on the basis of the input, for complex noun phrases (the [THING] who's [PROPERTY]) and simple questions ) (Is [THING] [ACTION]ing?) to yield a complex-question schema (Is [the [THING] who's [PROPERTY]] ACTIONing?). To investigate this possibility, 122 children aged 4-6 years were trained on simple questions (e.g., Is the bird cleaning?) and either (Experimental group) complex noun phrases (e.g., the bird who's sad) or (Control group) matched simple noun phrases (e.g., the sad bird). In fact, on most measures, the two groups did not differ on their ability to produce novel complex questions at test.

We can see a number of possible reasons for the failure to observe a training effect. The first, of course, is that there is no effect to find, and that children do not learn to form 
complex questions by combining schemas in the manner proposed. The second is that our study was under-powered in terms of the number of participants. The supplementary Bayesian analysis is consistent with this possibility with regard to the continuous measure (number of correct complex questions per group), even on the lenient scoring criteria that allow that for who substitution. However, inconsistent with this possibility, the categorical (chi-square) analysis found that (non-significantly) FEWER children in the Experimental than Control group (41 vs 42) produced at least one correct complex question at test. The third possibility is that the majority of children tested already had the linguistic knowledge and ability to produce correctly-formed complex questions, meaning that the intervention had little effect. Consistent with this possibility, over two-thirds of children in the control group were able to produce at least one complex question, despite not receiving the (by hypothesis) crucial element of training (complex noun phrases).

One difference between-groups did emerge: The Experimental Group produced significantly more questions than the Control group that used the particular complex noun phrase that was trained; i.e., the [THING] who's [PROPERTY], as opposed to the [THING] that's [PROPERTY]. That is, we observed a significant between-groups difference according to strict coding criteria that require the use of complementizer who, which the Experimental group heard during complex noun-phrase training. We can see three possible explanations for this finding.

The first is that this is simply a task effect: Irrespective of training, the majority of children were already relatively adept at producing complex questions with both that's and who's, but - all else being equal - preferred to use the former, perhaps due to a frequency effect (that's is around five times more frequent than who's in Google search results). On this account, children in the Experimental group learned nothing more than the experimenter seemed keen for them to use who's rather than that's, in contexts in which either is permissible.

The second possible explanation is that our manipulation was in fact successful in teaching the particular complex-question structure (Is [the [THING] who's [PROPERTY]] ACTIONing?). On this view, the majority of children began the study with a different complex-question structure based around that's (Is [the [THING] that's [PROPERTY]] ACTIONing?), which children in the Control Group used successfully at test. Children in the Experimental Group, however, were taught a NEW complex-question structure based around who's, and frequently used this structure at test. This possibility is consistent with a constructivist account of language acquisition in which children's syntactic structures are initially built around particular lexical items, here who's and that's (e.g., Tomasello, 2003). It is also consistent with an exemplar account under which individual lexical strings are never replaced by more abstract representations, but are retained and form the basis for subsequent productions, via either direct reuse or on-the-fly similarity-based analogy (e.g., Ambridge, submitted). Indeed, because the nouns, verbs and adjectives differed at training and test, participants cannot have been directly reusing lexical strings from training; some kind of generalization must have occurred.

The third possible explanation is that children already had abstract knowledge of complex-question formation at the start of the study, with our training giving children in the Experimental Group the tools to apply this knowledge to a relatively unfamiliar complementizer. For example, children might not have known before the study that who functions as a complementizer. Alternatively, they might have known in principle that both that and who are complementizers, but had very little experience in using the latter in production. This possibility is consistent with a generativist-nativist account, under which syntactic knowledge crucial for complex question formation (e.g., movement, structure 
dependence) is present at the start of language acquisition (e.g., Chomsky, 1980; Crain and Nakyama, 1987).

The present findings do not allow us to mediate between these three possibilities. We therefore end by suggesting a number of possible modifications that would allow future studies to do so and to provide a stronger test of the claim that complex questions are learned via schema-combination. First, future studies should use complex NPs with that's rather than who's in both the training for the Experimental Group and the target complex questions (or systematically explore the effect of using each). Since, all other things being equal, children seem to prefer to use that's than who's in complex NPs, this may allow for us to observe between-group differences that may have been masked by the experimenter's apparent insistence, during training, that children in the Experimental group use a dispreferred complementizer. The use of this more frequent complementizer during training may also allow for the testing of younger children. This would be highly desirable, given that one plausible reason for our failure to observe a between-groups difference was that around twothirds of children were already able to produce a correctly-formed complex question, even without training. It may also be beneficial to go further, by introducing a screening criterion, and including only children who do not yet show the ability to produce a complex question. This would allow for a more definitive test of the claim that it is possible to "create" the ability to produce complex questions, via training on simpe questions and complex noun phrases. Finally, future studies should ensure that they are appropriately powered, by using the findings of the present study to generate realistic effect size measures for power analysis (under a frequentist approach) or suitable priors (under a Bayesian approach). Given the high degree of variability between children with regard to their ability to produce complex questions, it may be that the present study was highly underpowered to observe an effect of training.

In summary, the question of how children learn to produce complex yes/no questions remains unanswered by the present training study. Although children in the experimental group did show some evidence of generalizing complex NPs learned during training into complex-question production at test, the present data do not allow us to mediate between generativist, constructivist and task-based accounts of this finding, leaving open the possibility of some role for innate knowledge.

\section{References}

Ambridge, B., \& Rowland, C.F. (2009). Predicting children's errors with negative questions: Testing a schema-combination account. Cognitive Linguistics, 20(2), 225-266.

Ambridge, B., Rowland, C. F., \& Pine, J. M. (2008). Is Structure Dependence an innate constraint? New experimental evidence from children's complex question production. Cognitive Science, 32(1), 222-255.

Ambridge, B., Rowland, C. F., Theakston, A. \& Tomasello, M. (2006) Comparing Different Accounts of Non-Inversion Errors in Children's Non-Subject Wh-Questions: 'What experimental data can tell us?' Journal of Child Language, 30(3) 519-557.

Barr, D. J., Levy, R., Scheepers, C., \& Tily, H. J. (2013). Random effects structure for confirmatory hypothesis testing: Keep it maximal. Journal of Memory and Language, 68(3), 255-278.

Bates, D., Maechler, M., Bolker, B. \& Walker, S. (2015). Fitting Linear Mixed-Effects Models Using lme4. Journal of Statistical Software, 67(1), 1-48. doi:10.18637/jss.v067.i01.

Berwick, R. C., Pietroski, P., Yankama, B., \& Chomsky, N. (2011). Poverty of the stimulus revisited. Cognitive Science, 35(7), 1207-1242. 
Bürkner, P. (2017). brms: An R Package for Bayesian Multilevel Models Using Stan. Journal of Statistical Software, 80(1), 1-28. doi:10.18637/jss.v080.i01.

Chomsky, N. (1980). In Piatelli-Palmarini, M. (1980). Language and Learning: The debate between Jean Piaget and Noam Chomsky. Cambridge, MA: Harvard University Press.

Clark, A., \& Eyraud, R. (2007). Polynomial time identification in the limit of substitutable context-free languages. Journal of Machine Learning Research, 8, 1725-1745.

Clark, A., \& Lappin, S. (2011). Linguistic nativism and the poverty of the stimulus. Oxford: Wiley-Blackwell.

Cowie, F. (1998). What's within? Nativism reconsidered. New York: Oxford University Press.

Crain, S. (1991). Language acquisition in the absence of experience. Behavioral and Brain Sciences, 14(4), 597-612.

Crain, S., \& Nakayama, M. (1987). Structure dependence in grammar formation. Language, $63,522-543$.

Crain, S., \& Pietroski, P. (2001). Nature, nurture and universal grammar. Linguistics and Philosophy, 24, 139-186.

Dąbrowska E., \& Lieven E.V.M. (2005). Towards a lexically specific grammar of children's question constructions. Cognitive Linguistics, 16(3), 437-474.

Dąbrowska, E. (2000). From formula to schema: The acquisition of English questions. Cognitive Linguistics, 11(1/2), 83-102.

Fitz, H., \& Chang, F. (2017). Meaningful questions: The acquisition of auxiliary inversion in a connectionist model of sentence production. Cognition, 166, 225-250.

Fodor, F. D., \& Crowther, C. (2002). Understanding stimulus poverty arguments. Linguistic Review, 19, 105-145.

Getz, H. R. (2018). Acquiring wanna: Beyond Universal Grammar. Language Acquisition. (online-first view).

Kam, X.-N. C., Stoyneshka, I., Tornyova, L., Fodor, J. D., \& Sakas, W. G. (2008). Bigrams and the richness of the stimulus. Cognitive Science, 32, 771-787.

Laurence, S., \& Margolis, E. (2001). The poverty of the stimulus argument. British Journal for the Philosophy of Science, 52, 217-276.

Legate, J. A., \& Yang, C. (2002). Empirical re-assessment of stimulus poverty arguments. Linguistic Review, 19, 151-162.

Lewis, J. D., \& Elman, J. L. (2001). Learnability and the statistical structure of language: Poverty of stimulus arguments revisited. In B. Skarabela, S. Fish, \& A. H. J. Do (Eds.), Proceedings of the twenty-sixth annual Boston University Conference on Language Development (pp. 359-370). Somerville, MA: Cascadilla

MacWhinney, B. (2004). A multiple process solution to the logical problem of language acquisition. Journal of Child Language, 31(4), 883-914.

Perfors, A., Tenenbaum, J. B., \& Regier, T. (2011). The learnability of abstract syntactic principles. Cognition, 118(3), 306-338.

Pinker, S. (1984). Language learnability and language development. Cambridge, MA: Harvard University Press.

Pullum, G. K., \& Scholz, B. C. (2002). Empirical assessment of stimulus poverty arguments. The Linguistic Review, 18(1-2), 9-50.

R Core Team (2017). R: A language and environment for statistical computing. R Foundation for Statistical Computing, Vienna, Austria. URL https://www.R-project.org/.

Reali, F., \& Christiansen, M. H. (2005). Uncovering the richness of the stimulus: Structure dependence and indirect statistical evidence. Cognitive Science, 29(6), 1007-1028. 
Regier, T., \& Gahl, S. (2004). Learning the unlearnable: The role of missing evidence. Cognition, 93(2), 147-155.

Rowland, C. F. (2007). Explaining errors in children's questions. Cognition, 104(1), 106-134.

Sakas, W. G., \& Fodor, J. D. (2012). Disambiguating syntactic triggers. Language Acquisition, 19(2), 83-143.

Sampson, G. (1989). Language acquisition: Growth or learning? Philosophical Papers, 18, 203-240.

Stemmer, N. (1981). A note on empiricism and structure-dependence. Journal of Child Language, 8, 649-663.

Tomasello, M. (2003). Constructing a language: A usage-based theory of language acquisition. Cambridge, MA: Harvard University Press.

Wexler, K. (1998). Very early parameter setting and the unique checking constraint: A new explanation of the optional infinitive stage. Lingua, 106(1-4), 23-79.

Wiig, E. H., Secord, W., \& Semel, E. M. (2004). CELF Preschool 2: Clinical evaluation of language fundamentals preschool. Pearson/PsychCorp. 